\title{
KARBON TERSIMPAN PADA BERBAGAI TIPE KERAPATAN TEGAKAN DI HUTAN RAKYAT DESA SUKOHARJO I KECAMATAN SUKOHARJO KABUPATEN PRINGSEWU
}

\author{
Carbon Stock in Various of Density at Private Forest of Sukoharjo I Village \\ Sukoharjo District Pringsewu Regency
}

Dio Ivando, Irwan Sukri Banuwa, Afif Bintoro

Jurusan Kehutanan, Fakultas Pertanian, Universitas Lampung

Jl. Prof. Dr. Soemantri Brojonegoro No. 1, Bandar Lampung.

E-mail:diopsw022@gmail.com

\begin{abstract}
Forests had an important role in carbon reserve and uptake: where this was one of efforts of global warming's impacts mitigation. The aim of this research was to know the effect of density in potential of carbon reserve and uptake in the private forest. Data collection was carried out by survey; then the collected data were analyzed for tree biomass, necromass, litter and ground plants, total of carbon stock in one area, suitability of carbon stock, $\mathrm{CO}_{2}$ absorbtion, and the differences in carbon stock and carbon uptake in each of density class. The result showed that, forests with low density were significantly lower in stored carbon and $\mathrm{CO}_{2}$ absorption, respectively 54.57 tons/ha and 200.27 tons/ha. In medium and high density forests, both the amount of stored carbon and $\mathrm{CO}_{2}$ uptake were no different. At medium density, stored carbon was 79.78 tons/ha, and $\mathrm{CO}_{2}$ absorption was 292.79 tons/ha. In high density, stored carbon was 92.94 tons/ha and $\mathrm{CO}_{2}$ absorption was 341.09 tons/ha.
\end{abstract}

Key words: carbon stock, carbon uptake, global warming, climate change.

\begin{abstract}
ABSTRAK
Hutan rakyat memiliki peran penting dalam penyimpanan dan penyerapan karbon; dimana hal ini merupakan salah satu upaya dalam mitigasi dampak pemanasan global. Penelitian ini bertujuan untuk mengetahui pengaruh kerapatan tegakan terhadap potensi cadangan dan serapan karbon di hutan rakyat. Pengumpulan data dilakukan dengan cara survey; kemudian data yang diperoleh dianallisis biomassa pohon, nekromassa, serasah dan tumbuhan bawah, cadangan karbon total dalam satu areal, kesesuaian cadangan karbon, penyerapan $\mathrm{CO}_{2}$, dan perbedaan cadangan dan serapan karbon pada tiap kelas kerapatan. Hasil penelitian menunjukkan bahwa, kawasan hutan rakyat Desa Sukoharjo I memiliki cadangan karbon rata-rata mencapai 72,73 ton/ha sehingga belum dapat dikategorikan sebagai hutan dengan kondisi yang baik dari segi jumlah cadangan karbon. Hutan dengan kerapatan rendah nyata lebih rendah karbon tersimpan dan serapan $\mathrm{CO}_{2}$ nya yaitu masing-masing 54,57 ton/Ha dan 200,27 ton/Ha. Pada hutan dengan kerapatan sedang dan tinggi, baik jumlah karbon tersimpan maupun serapan $\mathrm{CO}_{2}$ tidak berbeda. Pada kerapatan sedang, karbon tersimpan sebesar 79,78 ton/Ha, dan serapan $\mathrm{CO}_{2}$ sebesar
\end{abstract}


292,79 ton/Ha. Pada kerapatan tinggi, karbon tersimpan sebesar 92,94 ton/Ha dan serapan $\mathrm{CO}_{2}$ sebesar 341,09 ton/Ha. Petani hutan rakyat sebaiknya dapat memaksimalkan area hutan kerapatan rendah dengan meningkatkan populasi tegakan sehingga dapat meningkatkan cadangan dan serapan karbon.

Kata kunci: cadangan karbon, penyerapan karbon, pemanasan global, perubahan iklim.

\section{PENDAHULUAN}

Pemanasan global menyebabkan perubahan iklim yang sangat ekstrim. Hal ini tentu saja berdampak terhadap kehidupan masyarakat. Salah satu dampaknya adalah kemarau yang sangat panjang, sehingga produktivitas pertanian menurun akibat ketersediaan air yang terbatas (Arifin, 2004). Studi yang dilakukan Suarsana \& Wahyuni (2011) di Indramayu, Jawa Barat menunjukkan bagaimana petani mengalami kegagalan panen yang disebabkan oleh faktor cuaca dan iklim yang terus berubah dan sulit diprediksi.

Hutan rakyat yang tersebar di wilayah pedesaan berperan penting dalam upaya penanggulangan pemanasan global tersebut. Berdasarkan Permenhut No. 88 tahun 2003, hutan rakyat adalah hutan yang tumbuh di atas tanah yang dibebani hak milik maupun hak lainnya dengan ketentuan luas minimum 0,25 ha yang meliputi penutupan tanaman kayukayuan dan tanaman lainnya lebih dari $50 \%$. Widiyanto (2011) menyatakan bahwa hutan rakyat yang berbasis agroforestri lebih besar dalam penyimpanan cadangan karbonnya dibandingkan dengan hutan monokultur.

Total karbon tersimpan di hutan rakyat sangat tergantung kepada kerapatan tegakan di dalamnya. Kerapatan tegakan tersebut menjadi sangat penting karena terkait dengan sistem pengelolaan hutan yang diterapkan oleh masyarakat di lahan miliknya. Tujuan penelitian ini untuk mengetahui seberapa besar pengaruh kerapatan tegakan terhadap potensi cadangan dan serapan karbon di hutan rakyat.

\section{METODE}

\section{Lokasi dan Waktu Penelitian}

Penelitian dilaksanakan di hutan rakyat Desa Sukoharjo satu, Kecamatan Sukoharjo, Kabupaten Pringsewu pada bulan Maret - April 2018.

\section{Pengumpulan data}

Data yang dikumpulkan untuk digunakan dalam pendugaan biomassa meliputi:

1. Jenis pohon, tinggi pohon dan diameter pohon pada semua fase (semai, pancang, tiang dan pohon), jenis nekromasa, tinggi/panjang nekromasa, diameter nekromasa dan tingkat keutuhan nekromasa untuk pengukuran nekromasa.

2. Pengukuran biomasa seresah dan tumbuhan bawah yang meliputi; berat basah, berat basah contoh dan berat kering contoh.

3. Data kandungan cadangan dan serapan karbon masing-masing objek yang diperoleh dari hasil penghitungan total biomassa yang diperoleh.

4. Data perhitungan rancangan percobaan untuk pengujian perbandingan cadangan dan serapan karbon. 
Sampel ditentukan secara stratified sampling karena kondisi tegakan pada lokasi penelitian yang tidak seragam. Penentuan jumlah plot diperoleh berdasarkan rumus berikut (Indriyanto, 2006).

Luas areal hutan rakyat $=200 \mathrm{ha}=2.000 .000 \mathrm{~m}^{2}$

Intensitas sampling yang digunakan (IS) $=0,5 \%=0,005$

Maka didapat:

Luas seluruh plot yang diamati $=$ IS $x$ Luas Areal

$$
\begin{aligned}
& =0,005 \times 2000.000 \mathrm{~m}^{2} \\
& =10.000 \mathrm{~m}^{2}
\end{aligned}
$$

Luas petak ukur $=20 \mathrm{~m} \times 20 \mathrm{~m}=400 \mathrm{~m}^{2}$, sehingga didapat jumlah petak ukur yang dibuat adalah:

jumlah plot yang dibuat $=\frac{\text { luas seluruh plot yang diamati }}{\text { luas petak ukur }}$

$$
=\frac{10000 \mathrm{~m} 2}{400}=25 \text { plot }
$$

Berdasarkan referensi dari SK. Menteri Negara Lingkungan Hidup, No. 201 tahun 2004, bahwa kerapatan tinggi $\geq 1500$ pohon/ha, sedang $\geq 1000-<1500$ pohon/ha, dan rendah < 1000 pohon/ha, maka adapun perhitungan sampling jumlah pohon/plot dari tiap tipe kerapatan tegakan yaitu sebagai berikut.

$\sum N=\left(\left(\frac{\text { Luas Lahan Total }}{\text { Jumlah Plot Pengamatan }}\right) x \sum\right.$ Pohon per ha dari tiap kerapatan tegakan $)$

Keterangan:

$$
\text { : Luas plot }
$$

$\Sigma N$ : Jumlah sampel jumlah pohon/plot yang mewakili dari tiap tipe kerapatan hutan.

Maka diperoleh :

a. Kerapatan Tinggi : $\left(\left(\frac{200}{25}\right) x 1500\right): 400=\geq 30$ pohon $/$ plot

b. Kerapatan Sedang : $\left(\left(\frac{200}{25}\right) x 1000\right): 400=20-29$ pohon $/$ plot

c. Kerapatan Rendah : maka untuk kerapatan rendah sampel jumlah pohon/plot yang mewakili $\leq 20$ pohon/plot

Adapun jumlah ulangan yang ditentukan berdasarkan perlakuan dan jumlah plot yang disajikan Tabel 1.

Tabel 1. Ulasan ulangan per perlakuan (kerapatan tegakan)

Tabel 1. The repetition's review of treatments (wood's density)

\begin{tabular}{ccc}
\hline No & Perlakuan (Kerapatan Tegakan) & $\begin{array}{c}\text { Ulangan/Petak } \\
\text { Contoh }\end{array}$ \\
\hline 1. & Tinggi $(\geq 1500$ pohon $/$ ha $)=\geq 30$ pohon/plot & 8 \\
2 & Sedang $(\geq 1000-<1500$ pohon/ha $)=20-29$ pohon/plot & 8 \\
3 & Rendah $(<1000$ pohon/ha $)=\leq 20$ pohon/plot & 8 \\
\hline Total & & 24 \\
\hline
\end{tabular}




\section{Analisis Data}

\section{Biomassa Pohon dan Nekromassa}

Kandungan biomassa pohon dan nekromassa diperoleh dengan menggunakan persamaan allometrik (Tabel 2). Pengukuran nekromassa dilakukan terhadap pohon roboh, kayu atau batang tumbang yang sudah mati. Diameternya tetap diukur dan diestimasi sama dengan estimasi biomassa pohon hidup, hanya nilai persamaan allometrik dan berat jenisnya yang berbeda.

Tabel 2. Model persamaan allometrik yang digunakan

Tabel 2. Allometric equation model used

\begin{tabular}{cll}
\hline No & \multicolumn{1}{c}{ Jenis Tegakan } & \multicolumn{1}{c}{ Persamaan Allometrik } \\
\hline 1 & Mahoni* $^{*}$ & $\mathrm{BK}=0,902\left(\mathrm{D}^{2} \mathrm{H}\right)^{0,08}$ \\
2 & Sonokeling $^{*}$ & $\mathrm{BK}=0,745\left(\mathrm{D}^{2} \mathrm{H}\right)^{0,64}$ \\
3 & Jati $^{*}$ & $\mathrm{BK}=0,015\left(\mathrm{D}^{2} \mathrm{H}\right)^{1,08}$ \\
4 & Sengon $^{*}$ & $\mathrm{BK}=0,020\left(\mathrm{D}^{2} \mathrm{H}\right)^{0,93}$ \\
5 & Akasia* $^{*}$ & $\mathrm{BK}=0,077\left(\mathrm{D}^{2} \mathrm{H}\right)^{0,90}$ \\
6 & Pohon-pohon bercabang**$^{* *}$ & $\mathrm{BK}=0,11 \rho(\mathrm{D})^{2,62}$ \\
7 & Pohon tidak bercabang $^{\star *}$ & $\mathrm{BK}=\pi \rho \mathrm{D}^{2} \mathrm{H} / 40$ \\
8 & Kopi $^{* *}$ & $\mathrm{BK}=0,281(\mathrm{D})^{2,06}$ \\
9 & Palem $^{* *}$ & $\mathrm{BK}=\mathrm{EXP}(-2,134) \mathrm{D}^{2,530}$ \\
10 & Kakao $^{* *}$ & $\mathrm{BK}=0,1208(\mathrm{D})^{1,98}$ \\
\hline
\end{tabular}

Sumber: ${ }^{*}=$ Nugroho (2014).

** = Hairiah dan Rahayu (2007).

\section{Biomassa Serasah dan Tumbuhan Bawah}

Kandungan biomassa serasah dan tumbuhan bawah diperoleh dengan menggunakan rumus Biomass Expansion Factor (Brown, 1997).

\section{Penghitungan Cadangan Karbon Total dalam Suatu Areal}

Penghitungan cadangan karbon total dalam suatu areal menggunakan persamaan sebagai berikut (BSN, 2011) :

$$
C \text { total }=\left(\frac{\sum \text { Cplot }}{n \text { plot }}\right) \times \text { luas areal }
$$

\section{Kesesuaian Cadangan Karbon Berdasarkan IPCC (2006)}

Menurut Intergovernmental Panel on Climate Change (IPCC, 2006) bahwa, hutan yang baik dalam menyimpan cadangan karbon adalah hutan yang menyimpan rata-rata $>135$ ton/ha. Karbon tersimpan dihitung dengan rumus dari SNI (BSN, 2011).

$$
\text { C }=\text { Biomassa } \times 0,47
$$




\section{Penyerapan $\mathrm{CO}_{2}$}

Penghitungan jumlah serapan $\mathrm{CO}_{2}$ diperoleh dengan menggunakan rumus dari Hardjana (2010).

$$
\mathrm{WCO}_{2}=\mathrm{W}_{\mathrm{tc}} \times 3,67
$$

Keterangan:

$\mathrm{WCO}_{2}=$ banyaknya $\mathrm{CO}_{2}$ yang diserap (ton);

$\mathrm{W}_{\mathrm{tc}} \quad=$ berat total unsur karbon tegakan jenis dan umur tertentu (ton/ha);

3,67 = angka ekivalen/konversi unsur karbon (C) ke $\mathrm{CO}_{2}$ [massa atom $\mathrm{C}=12$ dan $\mathrm{O}=16$, $\mathrm{CO}_{2}=(1 \times 12)+(2 \times 16)=44 ;$ konversinya $\left.=>(44: 12)=3,67\right]$.

\section{Perbedaan Cadangan dan Serapan Karbon pada Tiap Kelas Kerapatan}

Perbandingan cadangan dan serapan karbon pada setiap kerapatan tegakan ditentukan dengan menggunakan Rancangan Acak Kelompok Lengkap (Hanafiah, 2011). Adapun tiga perlakuan yang digunakan yaitu berdasarkan tipe kerapatan tegakan hutan berdasarkan SK. Menteri Negara Lingkungan Hidup, No. 201 (2004) beserta jumlah ulangan yang disajikan dalam Tabel 1 . Selanjutnya data yang diperoleh dilakukan uji dengan sidik ragam dilanjutkan dengan uji Beda Nyata Taraf (BNT) 5\%.

\section{HASIL dan PEMBAHASAN}

\section{Total Karbon Tersimpan dalam Keseluruhan Plot}

Cadangan karbon dari tiga kelas kerapatan tegakan di hutan rakyat Desa Sukoharjo I disajikan pada Tabel 3.

Tabel 3. Karbon tersimpan pada kawasan hutan rakyat Desa Sukoharjo I

Tabel 3. Carbon stock in the private forest area of Sukoharjo I Village

\begin{tabular}{|c|c|c|c|c|c|c|c|c|}
\hline \multirow{3}{*}{ No } & \multirow{3}{*}{$\begin{array}{c}\text { Kelas } \\
\text { Kerapatan } \\
\text { (pohon/ha) }\end{array}$} & \multicolumn{6}{|c|}{ Karbon Tersimpan (ton/ha) } & \multirow{3}{*}{ Total (ton/ha) } \\
\hline & & \multicolumn{3}{|c|}{ Karbon Pohon (ton/ha) } & \multirow[b]{2}{*}{$\mathbf{N}$} & \multirow[b]{2}{*}{$\mathbf{S}$} & \multirow[b]{2}{*}{ TB } & \\
\hline & & $\mathbf{P}$ & $\mathbf{T}$ & $\mathrm{Pa}$ & & & & \\
\hline 1 & $<1000$ & 16.41 & 34.53 & 3.29 & 0.047 & 0.18 & 0.08 & 54.57 \\
\hline 2 & $\begin{array}{l}\geq 1000- \\
<1500\end{array}$ & 31.53 & 42.93 & 4.74 & 0.098 & 0.37 & 0.09 & 79.78 \\
\hline 3 & $\geq 1500$ & 27.18 & 60.48 & 4.72 & 0.07 & 0.39 & 0.07 & 92.94 \\
\hline \multicolumn{2}{|c|}{ Jumlah } & 75.12 & 137.96 & 12.76 & 0.21 & 0.95 & 0.26 & 227.29 \\
\hline \multicolumn{2}{|c|}{ Rata-rata } & 25.04 & 45.98 & 4.25 & 0.07 & 0.31 & 0.08 & 72.73 \\
\hline \multicolumn{2}{|c|}{ Persentase \% } & $33 \%$ & $60.7 \%$ & $5.6 \%$ & $0.09 \%$ & $0.4 \%$ & $0.1 \%$ & $100 \%$ \\
\hline
\end{tabular}

Keterangan:

$\mathrm{P}$ : Pohon; T : Tiang ; Pa : Pancang ; N : Nekromassa ; S : Serasah ;

TB : Tumbuhan bawah 
Cadangan karbon rata-rata di Hutan Rakyat Desa Sukoharjo I masih tergolong kurang baik yaitu 72,73 ton/ha (Tabel 3). Menurut Intergovernmental Panel on Climate Change atau disingkat IPCC (2006), hutan yang berkatagori baik memiliki kandungan karbon sebesar 138 ton/ha atau lebih. Faktor penyebab dari masalah tersebut adalah kawasan kerapatan rendah yang mempunyai cadangan karbon yang paling sedikit karena kurang dimaksimalkan para petani untuk memprioritaskan tanaman kehutanan. Selain itu, dari angka rata-rata diameter biomassa pohon di hutan rakyat Desa Sukoharjo I masih belum dalam ukuran diameter yang relatif besar yaitu 20-58 cm. Padahal diameter pohon merupakan salah satu indikator yang mempengaruhi jumlah cadangan karbon (Putri \& Wulandari, 2015). Adapun hasil penelitian sejenis di kawasan Repong Damar menunjukkan bahwa diameter 20-108 cm dapat menghasilkan cadangan karbon mencapai 201,23 ton/Ha (Bhaskara, 2017). Hal ini sesuai dengan pernyataan Yamani (2013), bahwa batang merupakan bagian pohon berkayu sebagai tempat penyimpanan cadangan karbon hasil dari fotosintesis untuk pertumbuhannya.

Adapun sebagai perbandingan, studi yang dilakukan Ristiara (2016) yaitu di hutan rakyat Pekon Kelungu, Tanggamus memiliki katagori yang sama dengan hutan Rakyat Desa Sukoharjo I. Hutan rakyat Pekon Kelungu mempunyai cadangan karbon rata-rata 101,61 ton/ha. Penyebabnya adalah para petani kurang memaksimalkan tanaman berkayu atau tanaman kehutanan dan kurang memperhatikan faktor pemilihan jenis. Aspek pemilihan jenis mempengaruhi jumlah cadangan karbon hal ini dibuktikan dengan studi yang dilakukan oleh Asyisanti (2004) di hutan rakyat di Desa Karyasari, Kabupaten Bogor, Jawa Barat, bahwa cadangan karbon di hutan rakyat tersebut mencapai 192,33 ton/ha dimana hutan rakyat tersebut didominasi oleh tegakan pohon afrika dan pohon buah-buahan (rambutan dan lain lain).

\section{Penyerapan $\mathrm{CO}_{2}$ di Hutan Rakyat Desa Sukoharjo I}

Serapan karbon dari tiga kelas kerapatan tegakan di hutan rakyat Desa Sukoharjo I disajikan pada Tabel 5.

Tabel 5. Jumlah penyerapan karbon dari ketiga kelas kerapatan tegakan hutan rakyat Desa Sukoharjo I.

Tabel 5. The amount of carbon uptake from the three classes of stand density of the private forest of Sukoharjo I Village.

\begin{tabular}{clcc}
\hline No & $\begin{array}{c}\text { Kelas Kerapatan } \\
\text { Tegakan (pohon/ha) }\end{array}$ & $\begin{array}{c}\text { KarbonTersimpan } \\
\text { (ton/ha) }\end{array}$ & $\begin{array}{c}\text { Potensi Serapan } \mathbf{C O}_{\mathbf{2}} \\
\text { (ton/ha) }\end{array}$ \\
\hline 1 & Rendah $(<1000)$ & 54,57 & 200,27 \\
2 & Sedang $(1000-<1500)$ & 79,78 & 292,79 \\
3 & Tinggi $(>1500)$ & 92,94 & 341,09 \\
\hline \multirow{2}{*}{ Jumlah } & 227,29 & 834,15 \\
\hline & & \\
Rata-rata & 72,73 & 266.92 \\
\hline
\end{tabular}

\section{Perbandingan Cadangan dan Serapan Karbon pada tiap Kerapatan Tegakan}

Berdasarkan uji BNT5 \% pada Tabel 6 nyata bahwa, pada kerapatan rendah memiliki nilai cadangan karbon yang paling rendah dibandingkan dengan kerapatan sedang dan tinggi yang ditunjukan dengan nilai signifikansi yang berbeda nyata. Sementara itu, nilai cadangan karbon antara kerapatan sedang dengan kerapatan tinggi tidak menunjukkan 
perbedaan. Namun demikian masih dapat dikatakan bahwa, kerapatan tegakan berpengaruh dalam jumlah cadangan karbon. Hal ini sesuai dengan pernyataan Asril (2009), yang menyatakan bahwa faktor yang mempengaruhi banyaknya karbon yang tersimpan adalah kerapatan tegakan, semakin besar kerapatan suatu jenis pohon maka semakin besar pula cadangan karbon.

Tabel 6. Pengaruh tingkat kerapatan tegakan terhadap jumlah karbon tersimpan di hutan rakyat Desa Sukoharjo I

Tabel 6. The level of density's effect about in carbon stock at private forest of Sukoharjo I Village

\begin{tabular}{lccc}
\hline & \multicolumn{2}{c}{ Cadangan Karbon (ton/ha) } & \\
\cline { 2 - 3 } \multicolumn{1}{c}{ Perlakuan } & $\begin{array}{c}\text { Sebelum } \\
\text { Ditransformasi }\end{array}$ & $\sqrt{\boldsymbol{x}}$ & Signifikansi \\
\cline { 2 - 3 } Rendah & 54,57 & 3,05 & $\mathrm{a}$ \\
Sedang & 79,78 & 3,62 & $\mathrm{~b}$ \\
Tinggi & 92,94 & 3,61 & $\mathrm{~B}$ \\
\hline
\end{tabular}

BNT $5 \%$

0,50

Keterangan: Angka sekolom yang diikuti huruf sama tidak berbeda menurut uji BNT 5\%.

Kerapatan rendah memiliki nilai serapan karbon yang nyata lebih rendah dibandingkan kerapatan sedang dan tinggi (Tabel 7). Sementara itu, nilai serapan karbon antara kerapatan sedang dengan kerapatan tinggi tidak menunjukkan perbedaan. Namun demikian masih dapat dikatakan bahwa, semakin tinggi kerapatan tegakan maka semakin tinggi tingkat penyerapan karbon. Jumlah penyerapan $\mathrm{CO}_{2}$ di Hutan Rakyat Desa Sukoharjo I dipengaruhi jumlah biomassa berikut kandungan karbonnya, serta tingkat kerapatan tegakan di lokasi tersebut. Hal ini sesuai dengan pernyataan Natalia et al. (2013), bahwa serapan karbon sangat dipengaruhi oleh biomassa, oleh karena itu apapun yang menyebabkan bertambah atau berkurangnya potensi biomassa akan berpengaruh pula serapan karbon. Selain itu, menurut Sugirahayu \& Rusdiana (2011), bahwa penyerapan karbon dipengaruhi oleh jumlah dan diameter pohon, kerapatan tegakan dan faktor lingkungan.

Tabel 7. Pengaruh tingkat kerapatan tegakan terhadap serapan karbon di Hutan Rakyat Desa Sukoharjo I

Tabel 7. The level of density's effect of carbon uptake in the Private Forest of Sukoharjo I Village

\begin{tabular}{cccc}
\hline & \multicolumn{2}{c}{ Serapan Karbon (ton/ha) } & \\
\cline { 2 - 3 } Perlakuan & $\begin{array}{c}\text { Sebelum } \\
\text { Ditransformasi }\end{array}$ & $\sqrt{\boldsymbol{x}}$ & Signifikansi \\
\hline Rendah & 200,27 & 5,73 & $\mathrm{~A}$ \\
Sedang & 292,79 & 6,84 & $\mathrm{~B}$ \\
Tinggi & 341,09 & 6,81 & $\mathrm{~B}$ \\
\hline BNT 5\% & & 0,97 & \\
\hline Keterangan: Angka sekolom yang diikuti huruf sama tidak berbeda menurut uji BNT 5\%.
\end{tabular}




\section{KESIMPULAN}

Hutan rakyat Desa Sukoharjo I belum tergolong hutan yang baik dalam penyimpanan cadangan karbon karena hanya memiliki cadangan karbon rata-rata mencapai 72,73 ton/ha. Kandungan karbon tersimpan dan serapan $\mathrm{CO}_{2}$ nyata lebih rendah pada hutan dengan kerapatan rendah yaitu masing-masing 54,57 ton/Ha dan 200,27 ton/Ha. Kandungan karbon tersimpan maupun serapan $\mathrm{CO}_{2}$ tidak berbeda antara hutan kerapatan sedang dengan tinggi. Pada kerapatan sedang, karbon tersimpan sebesar 79,78 ton/ $\mathrm{Ha}$, dan serapan $\mathrm{CO}_{2}$ sebesar 292,79 ton/Ha. Pada kerapatan tinggi, karbon tersimpan sebesar 92,94 ton/Ha dan serapan $\mathrm{CO}_{2}$ sebesar 341,09 ton/Ha. Hutan dengan kerapatan rendah sebaiknya lebih dimaksimalkan dalam produktivitas cadangan dan serapan karbon oleh para petani hutan rakyat yaitu dengan memprioritaskan tanaman kehutanan atau tanaman berkayu lainnya.

\section{DAFTAR PUSTAKA}

Arifin, B. (2004). Analisis Ekonomi Pertanian Indonesia. Jakarta: Kompas.

Asril. (2009). Pendugaan Cadangan Karbon di Atas Permukaan Tanah Rawa Gambut di Stasiun Penelitian Suaq Balimbing Kabupaten Aceh Selatan Propinsi Nanggroe Aceh Darussalam. Tesis. Medan: Universitas Sumatera Utara.

Asyisanti. (2004). Potensi Karbon di Atas Permukaan Tanah Pada Hutan Rakyat (Studi Kasus di Desa Karyasari, Kabupaten Bogor, Jawa Barat). Tesis. Bogor: Fakultas Kehutanan, Institut Pertanian Bogor.

[BSN] Badan Standarisasi Nasional. (2011). Pengukuran \& Perhitungan Cadangan Karbon. Pengukuran Lapangan untuk Penaksiran Cadangan Karbon Hutan (Ground Based Forest Carbon Accounting). Jakarta: Badan Standarisasi Nasional.

Brown, S. (1997). Estimating Biomass and Biomass Change of Tropical Forest, A Primer. Rome: FAO Forestry Paper 134.

Bhaskara, D.R. (2017). Karbon Tersimpan pada Repong Damar Pekon Pahmungan Kecamatan Pesisir Tengah Kabupaten Pesisir Barat. Skripsi. Lampung: Universitas Lampung.

Hairiah, K. \& Rahayu, S. (2007). Pengukuran Karbon Tersimpan di Berbagai Macam Penggunaan Lahan. Bogor: World Agroforestry Center, ICRAF,SEA.

Hanafiah, K.A. (2011). Rancangan Percobaan. Jakarta: Rajawali Press.

Hardjana, A.K. (2010). Potensi biomassa dan karbon pada hutan tanaman Acacia mangium di HTI PT Surya Hutani Jaya, Kalimantan Timur. Jurnal Penelitian Sosial dan Ekonomi, $7(4), 237-249$.

Indriyanto. (2006). Ekologi Hutan. Jakarta: PT Bumi Aksara.

[IPCC] Intergovermental Panel on Climate Change. (2006). Intergovermental Panel on Climate Change Guidelones for National Greenhouse Gas Inventories. Kanagawa: IGES.

Natalia, D., Yuwono, S.B. \& Qurniati, R. (2014). Potensi penyerapan karbon pada sistem agroforestri di Desa Pesawaran Indah Kecamatan Padang Cermin Kabupaten Pesawaran Provinsi Lampung. Jurnal Sylva Lestari, 2(1), 11-20.

Nugroho, D. (2014). Menghitung Cadangan Karbon di Hutan Rakyat Panduan bagi Para Pendamping Petani Hutan Rakyat. Yogyakarta: Biro Penerbit ARuPA.

Putri, A.H.M. \& Wulandari, C. (2015). Potensi penyerapan karbon pada tegakan damar mata kucing (Shorea javanica) di Pekon Gunung Kemala Krui Lampung Barat. Jurnal Sylva Lestari, 3(2), 13-20. 
Ristiara, L. (2016). Estimasi Karbon Tersimpan pada Hutan Rakyat di Pekon Kelunggu Kabupaten Tanggamus. Skripsi. Bandar Lampung: Universitas Lampung.

Suarsana, M. \& Wahyuni, P.S. (2011). Global warming: Ancaman nyata sektor pertanian dan upaya mengatasi kadar $\mathrm{CO}_{2}$ atmosfer. Jurnal Sains dan Teknologi, 11(1), 31-37.

Sugirahayu, L. \& Rusdiana, O. (2011). Perbandingan simpanan karbon pada beberapa tutupan lahan di Kabupaten Paser, Kalimantan Timur berdasarkan sifat fisik dan kimia tanahnya. Jurnal Silvikultur Tropika, 2(3), 149-155.

Widiyanto, A. (2011). Mitigasi Perubahan Iklim Melalui Agroforestri: Sebuah Prespektif. Ciamis: Balai Penelitian Agroforestri.

Yamani, A. (2013). Studi kandungan karbon pada hutan alam sekunder di Hutan Pendidikan Mandiangin Fakultas Kehutanan Unlam. Jurnal Hutan Tropis, 1(1), 85-91. 